\title{
Unusual localization of vegetations in a native aortic valve infective endocarditis
}

\author{
Samuel Bruls ${ }^{1}$, Raluca Dulgheru ${ }^{1}$, Patrizio LANCELLOTTI ${ }^{1}$, and Jean Olivier Defraigne ${ }^{1}$ \\ ${ }^{1}$ Central University Hospital of Liege
}

June 17, 2021

\begin{abstract}
In case of valvular infective endocarditis, the infection is mainly localized on the flow side of the valves or at damaged valvular endothelium. We describe a rare case of an aortic valvular inefctive endocarditis with an aortic-valve vegetation situated on the aortic side of the valve. We believe this is the first description of this unusual localization of vegetations in a native aortic valve.
\end{abstract}

\section{Hosted file}

Manuscript final.doc available at https://authorea.com/users/420158/articles/526526-unusuallocalization-of-vegetations-in-a-native-aortic-valve-infective-endocarditis 


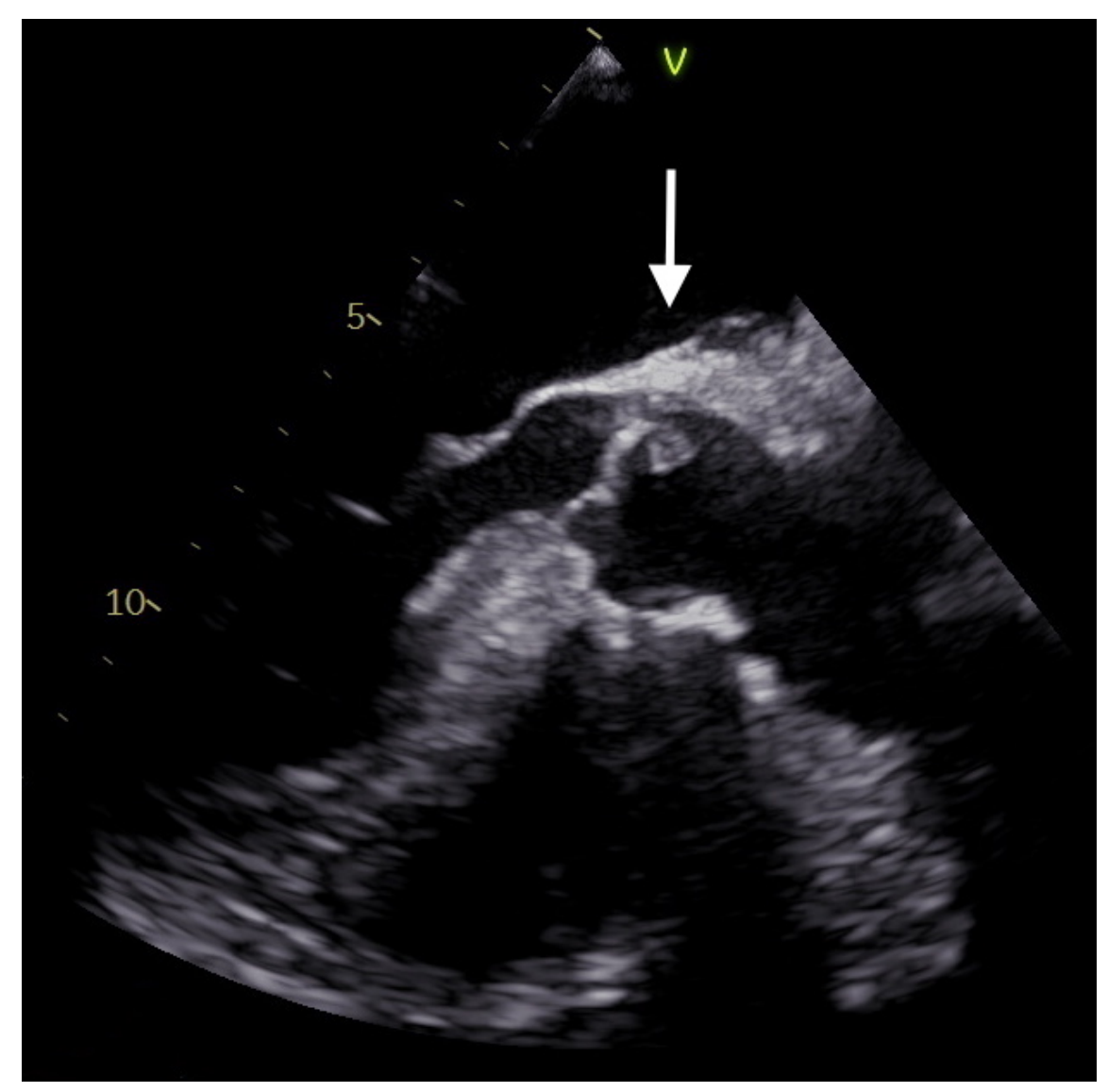



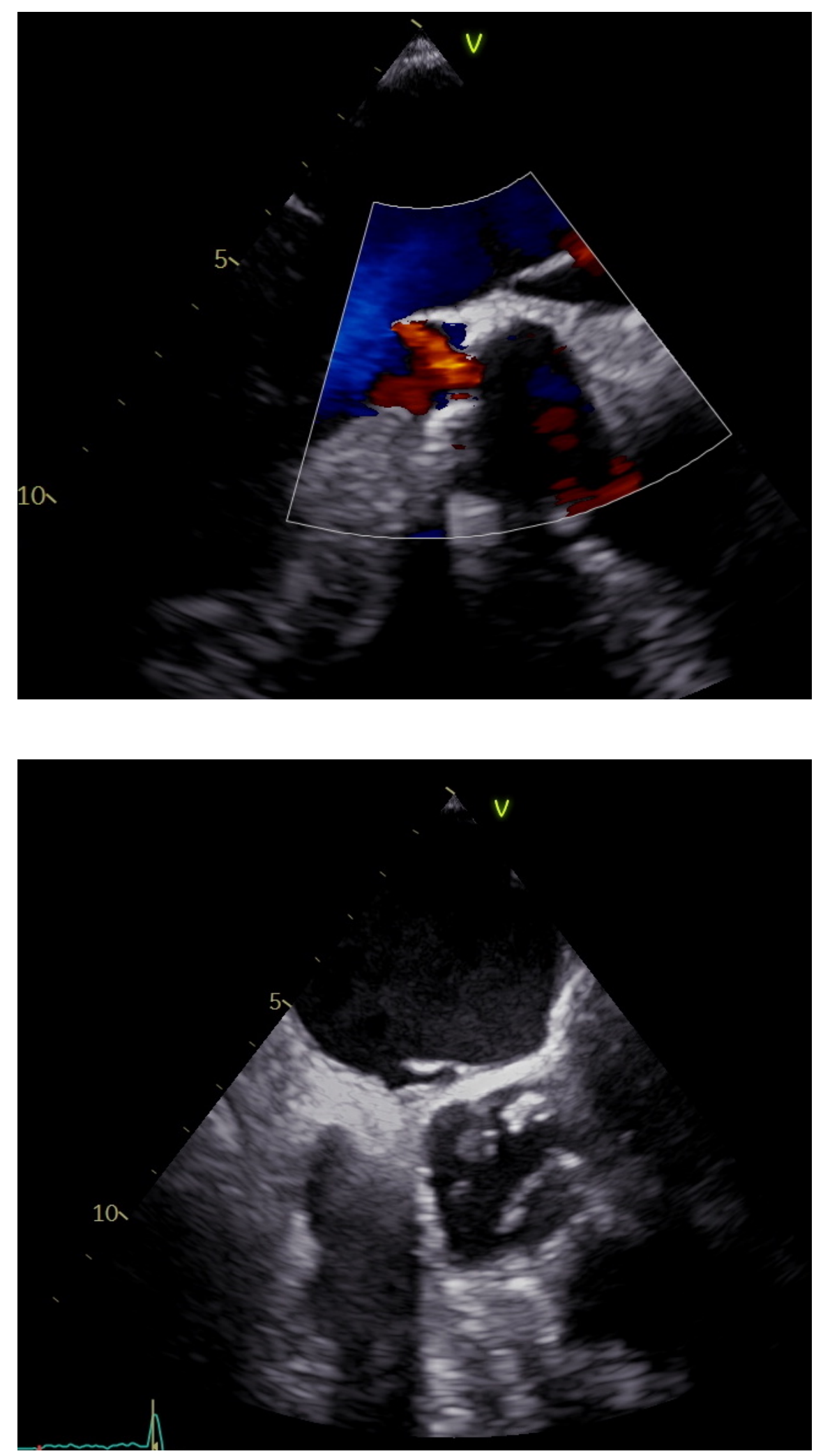


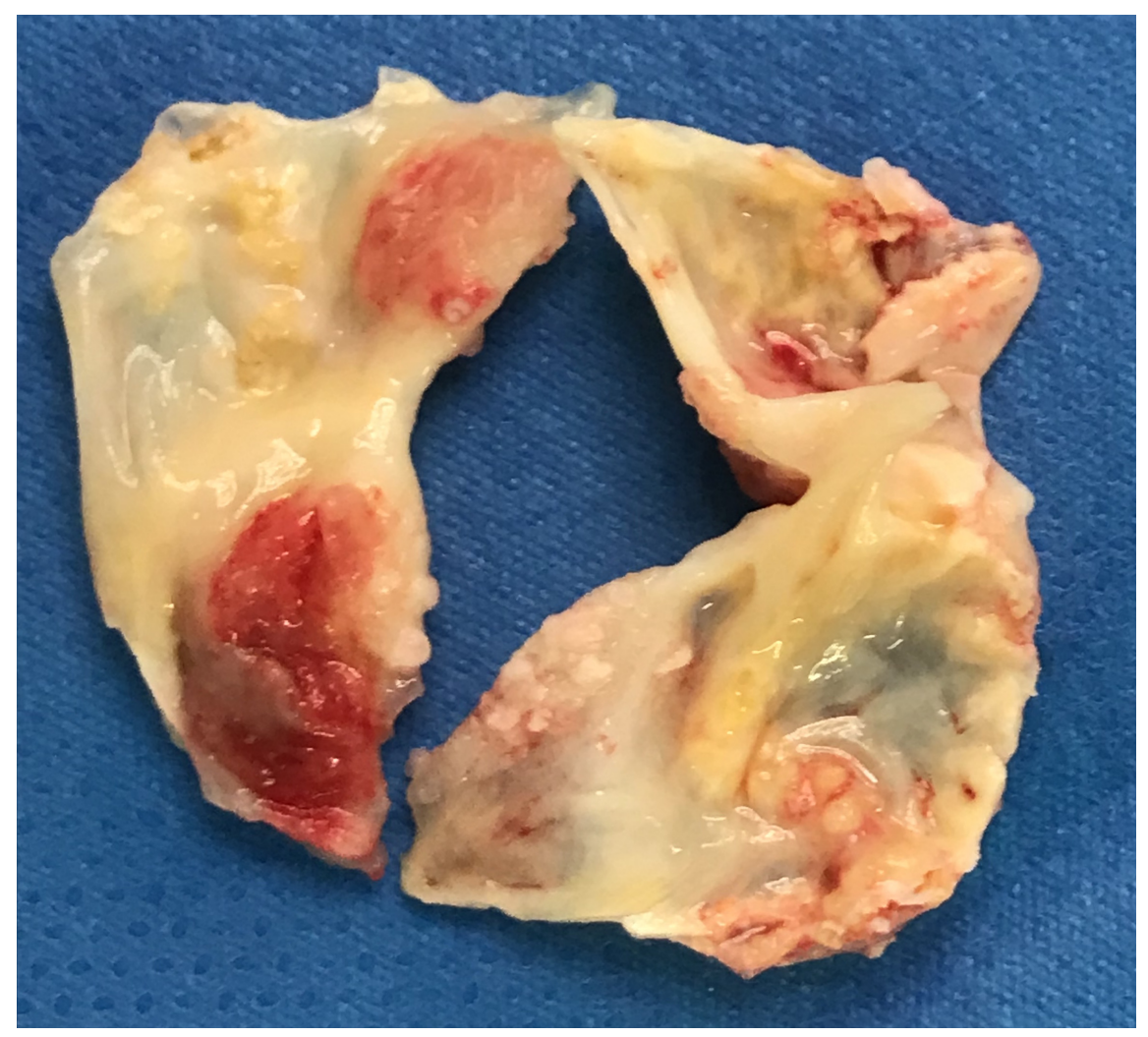

